\title{
Trophic niche but not abundance of Collembola and Oribatida changes with drought and farming system
}

\author{
Svenja Meyer $^{\text {Corresp., } 1}$, Dominika Kundel ${ }^{2,3}$, Klaus Birkhofer ${ }^{4}$, Andreas Fließbach $^{3}$, Stefan Scheu ${ }^{1,5}$ \\ ${ }^{1}$ Animal Ecology, J.F. Blumenbach Institute for Zoology and Anthropology, University of Göttingen, Göttingen, Germany \\ 2 Ecology, Department of Biology, University of Konstanz, Konstanz, Germany \\ 3 Department of Soil Sciences, Research Institute of Organic Agriculture (FiBL), Frick, Switzerland \\ 4 Department of Ecology, Brandenburg University of Technology, Cottbus, Germany \\ ${ }^{5}$ Centre of Biodiversity and Sustainable Land Use, University of Göttingen, Göttingen, Germany \\ Corresponding Author: Svenja Meyer \\ Email address: smeyer6@gwdg.de
}

Higher frequencies of summer droughts are predicted to change soil conditions in the future affecting soil fauna communities and their biotic interactions. In agroecosystems drought effects on soil biota may be modulated by different management practices that alter the availability of different food resources. Recent studies on the effect of drought on soil microarthropods focused on measures of abundance and diversity. We here additionally investigated shifts in trophic niches of Collembola and Oribatida as indicated by stable isotope analysis $\left({ }^{13} \mathrm{C}\right.$ and $\left.{ }^{15} \mathrm{~N}\right)$. We simulated short-term summer drought by excluding $65 \%$ of the ambient precipitation in conventionally and organically managed winter wheat fields on the DOK trial in Switzerland. Stable isotope values suggest that plant litter and root exudates were the most important resources for Collembola (Isotoma caerulea, Isotomurus maculatus and Orchesella villosa) and older plant material and microorganisms for Oribatida (Scheloribates laevigatus and Tectocepheus sarekensis). Drought treatment and farming systems did not affect abundances of the studied species. However, isotope values of some species increased in organically managed fields indicating a higher proportion of microorganisms in their diet. Trophic niche size, a measure of both isotope values combined, decreased with drought and under organic farming in some species presumably due to favored use of plants as basal resource instead of algae and microorganisms. Overall, our results suggest that the flexible usage of resources may buffer effects of drought and management practices on the abundance of microarthropods in agricultural systems. 


\section{Trophic niche but not abundance of Collembola and Oribatida}

2 changes with drought and farming system

3 Svenja Meyer ${ }^{1}$, Dominika Kundel ${ }^{2,3}$, Klaus Birkhofer ${ }^{4}$, Andreas Fliessbach ${ }^{3}$, Stefan Scheu ${ }^{1,5}$

4

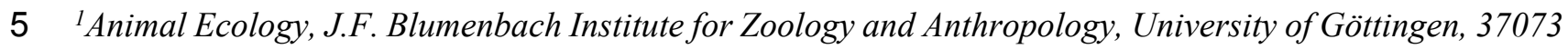

6 Göttingen, Germany

7 2Ecology, Department of Biology, University of Konstanz, 78464 Konstanz, Germany

$8{ }^{3}$ Department of Soil Sciences, Research Institute of Organic Agriculture (FiBL), 5070 Frick, Switzerland

$9{ }^{4}$ Department of Ecology, Brandenburg University of Technology, 03046 Cottbus, Germany

$10{ }^{5}$ Centre of Biodiversity and Sustainable Land Use, University of Göttingen, 37073 Göttingen, Germany

13 Corresponding author:

14 Svenja Meyer

15 Untere Karspüle 2, 37073 Göttingen

16 Email address: smeyer6@gwdg.de 


\section{Introduction}

18 Soils in agricultural systems are not well buffered against changes in climate and therefore are likely to undergo profound transformations in face of future climate change. For Central Europe, the predicted climate changes include reduced precipitation during summer with consequent higher frequency of summer droughts (EEA 2017; Samaniego et al. 2018). The resulting lower soil moisture levels are not only relevant for the water supply of crops, but also for soil biota and associated ecosystem functions, such as nutrient cycling and soil aggregate formation (Geng et al. 2015; Spinoni et al. 2015; Zhang et al. 2018). Studies on the effect of drought on soil microarthropods have focused on measures of diversity and abundance, and indicate either a negative (Frampton et al. 2000; Blankinship et al. 2011; Karbol et al. 2011; Vestergård et al. 2015) or no response (Holmstrup et al. 2013; Krab et al. 2014).

One way to better understand the response of soil microarthropods to increased drought conditions and to further connect them to processes such as nutrient cycling is to investigate changes in their feeding behavior. Soil organisms interact with each other in a food web with links of different strengths between the individual components (Scheu 1998; Hines et al. 2015; Potapov et al. 2019). From the perspective of soil microarthropods, some of these links may be particularly vulnerable to a decrease in soil moisture (Barreto et al. 2021). Bacteria and nematodes, for example, need water films between soil particles to move, grow and survive (Erktan et al. 2020), and thus are only available as a food resource for microarthropods at sufficiently high soil moisture levels. Further, drought may reduce plant biomass and thereby major basal resources of soil food webs such as leaf litter, roots and rhizodeposits (Jaleel et al. 2009; Scheunemann et al. 2015). Negative effects on these basal resources of soil food webs may cascade up to higher trophic levels resulting in decreased abundance and changes in trophic niches towards more drought-resistant resources like soil organic matter. In agricultural systems trophic links are likely to vary with soil characteristics and management practices. The availability of resources for microarthropods, such as soil organic matter and microorganisms, differs substantially between management systems receiving organic or mineral fertilizers (Mäder et al. 2002; Birkhofer et al. 2008). Organically managed fields are characterized by higher abundances of microorganisms with a larger proportion of fungi compared to systems receiving only mineral fertilizer (Haubert et al. 2009). These form an important food resource for Collembola and Oribatida (Schneider et al. 2004; Chahartaghi et al. 
48 2005; Pollierer and Scheu 2021). Such differences in resource availability are likely to change 49 the feeding behavior of microarthropods, which has been shown for several other compartments 50 of soil food webs before (Haubert et al. 2009; MacFadyen et al. 2009; Birkhofer et al. 2011).

51 However, the few studies that include Collembola and Oribatida species only documented subtle 52 or no niche shifts with changes in environmental conditions (Korotkevich et al. 2018; Krause et 53 al. 2019).

54 In this study we use stable isotope analysis to characterize trophic niches of abundant species of 55 Collembola and Oribatida in replicated plots of long-term conventional and organic farming 56 systems. The ratio of the stable isotopes of nitrogen allows insight into the trophic level of 57 consumers due to enrichment in ${ }^{15} \mathrm{~N}$ in higher trophic levels, whereas the ratio of carbon stable 58 isotopes reflects the utilization of basal resources (Post 2002; Potapov et al. 2019). In previous 59 studies, stable isotope analysis has mainly been used to characterize the trophic structure of soil animal communities of different habitats and to generally clarify the usage of basal resources by certain taxonomic groups (Scheu and Falca 2000; Potapov et al. 2019). Only few studies employed stable isotope analysis to investigate the response of the trophic structure of soil food webs to different experimental treatments such as different farming systems (Haubert et al. 2009; Birkhofer et al. 2011; Susanti et al. 2021) or track changes in trophic niches induced by changes in environmental conditions (Birkhofer et al. 2016; Korotkevich et al. 2018; Krause et al. 2019). Dry conditions were shown to increase $\delta^{15} \mathrm{~N}$ values of Oribatida in forests possibly due to trophic shifts resulting from changes in microbial activity and community composition (Melguizo-Ruiz et al. 2017). Further, drought is likely to increase periods of starvation due to lower availability of resources that depend on high soil moisture. Starvation has been shown to increase $\delta^{13} \mathrm{C}$ and $\delta^{15} \mathrm{~N}$ values of the body tissue of animals in part as a result of metabolizing lipids, which are depleted in ${ }^{13} \mathrm{C}$ (Adams and Sterner 2000; Oelbermann and Scheu 2002; Haubert et al. 2009). Effects of drought on stable isotope ratios of microarthropods are likely to differ between different farming systems which comprise differently structured soil food webs (Birkhofer et al. 2011). Additionally, a reduction in soil moisture can be buffered in organically managed fields due to high soil organic carbon contents that result in more structured soils with a higher water holding capacity (Lotter et al. 2003; Kundel et al. 2020). However, the interactive effects of experimental drought and farming systems on the trophic behavior of microarthropods, to the best of our knowledge, have not been investigated before. 
79 Besides looking into mean values of stable isotope ratios of carbon and nitrogen separately, we

80 further include estimates of trophic niche sizes combining measurements of both isotopes in a 81 two-dimensional space (Bearhop et al. 2004; Jackson et al. 2011). Niche sizes are proposed to

82 become narrower in stable, deterministic environments due to more specialization (Giller 1996).

83 In line with this assumption empirical studies on trophic niches of soil animals suggest that 84 trophic niche sizes are smaller in undisturbed compared to disturbed habitats (Korotkevich et al. 85 2018). We, therefore, expected disturbances such as drought to enlarge the trophic niche of 86 Collembola and Oribatida. Likewise, regarding farming systems, we assumed that a conventional 87 system based on the input of mineral fertilizer without organic fertilizers to represent a more disturbed system compared to an organically managed system receiving manure. Conditions in the conventional system should hence force consumers to enlarge their trophic niche. Here, we investigated the trophic niches of individual species of Collembola and Oribatida as affected by experimental drought and conventional versus organic farming. We hypothesized (1) trophic niches to vary among species indicating the occupation of different trophic levels and the utilization of different basal resources with intraspecific differences between the conventional and the organic farming system. Further, we hypothesized (2) drought to change the trophic ecology of the studied microarthropod species expressed by increased $\delta^{13} \mathrm{C}$ and $\delta^{15} \mathrm{~N}$ values of individual species with this being more pronounced in conventionally compared to organically managed fields. We further hypothesized that (3) trophic niche sizes are larger in the experimental drought treatments and the conventional farming system as more severely disturbed systems.

\section{Materials \& Methods}

Study site

The study was performed in 2017 in the DOK trial, an agricultural long-term field experiment established in 1978 comparing different organic and conventional farming systems. The DOK trial is located in Therwil, Switzerland, at $300 \mathrm{~m}$ above sea level on a Haplic Luvisol on deep deposits of alluvial loess (Fließbach et al. 2007). The mean annual temperature over the last five years was $10.5^{\circ} \mathrm{C}$ and the mean annual precipitation was $842 \mathrm{~mm}$ (Krause et al. 2020). For this study we used winter wheat fields with soybean as the previous crop. The experimental fields were organized in four blocks each comprising a conventionally and an organically managed 
110 field (factor farming system, CONMIN and BIODYN systems of the DOK trial, respectively). 111 Conventionally managed fields received mineral fertilizer (40 - $60 \mathrm{~kg} \mathrm{~N} / \mathrm{ha}$ in March, April and 112 May), herbicides (0.1 1/ha of Husar OD, Bayer, Zollikofen, Switzerland, and 1 1/ha of Mondera, 113 Switzerland, once in March), insecticides (0.1 1/ha of Audienz, Omya, Oftringen, Switzerland, in 114 May) and fungicides (1.5 1/ha Pronto Plus in April and 1 1/ha AviatorXpro and Miros FL in May; 115 all Bayer) as well as plant growth regulators (1.5 1/ha Cycocel extra, Omya, in March).

116 Organically managed fields received only organic fertilizers (farmyard manure, compost and 117 slurry), biodynamic preparations and mechanical weed control (Krause et al. 2020; Kundel et al. 118 2020). All fields were ploughed up to a depth of $20 \mathrm{~cm}$ and seedbed preparation was done with a 119 tooth harrow to a depth of $10 \mathrm{~cm}$. In both systems 415 grains $/ \mathrm{m}^{2}$ were sown. All fields followed 120 the same 7-year crop rotation with soybean as the preceding crop. On each field one drought 121 treatment and one control plot were established (factor drought). We simulated drought by using 122 experimental rainout-shelters that excluded $65 \%$ of the precipitation (for details on the shelter 123 construction see Kundel et al. 2018). On the control plots, we established a similar shelter 124 construction with the difference, that it did not reduce precipitation entering the plot. Thereby, 125 we accounted for possible side effects caused by the roof construction itself (Kundel et al. 2018).

127 Sampling

128 Samples were taken in May, eight weeks after the establishment of the experiment, with soil 129 cores of 5 and $20 \mathrm{~cm}$ diameter to a depth of $10 \mathrm{~cm}$ in the center of the plots $(\mathrm{n}=16)$.

130 Microarthropods with high densities, in our case the Collembola Mesaphorura sp. and Oribatida, 131 were taken from the $5 \mathrm{~cm}$ cores. For the other Collembola, i.e. Isotoma caerulea, Isotomurus 132 maculatus and Orchesella villosa, abundances in the small cores were too low to obtain enough 133 material for stable isotope measurements, so we took them from the large soil cores that were 134 initially taken to extract macrofauna. Soil animals were extracted from intact soil cores by 135 gradually increasing the temperature from 25 to $55^{\circ} \mathrm{C}$ over ten days (Macfadyen 1961; Kempson 136 et al. 1963), collected into a glycol-water solution (1:1) in canisters underneath the soil coresand 137 stored in $70 \%$ ethanol. We first sorted the extracted animals to order level under a 138 stereomicroscope (Stemi 2000; Zeiss). Thereafter, Collembola and Oribatida were identified to 139 species or genus level under the microscope (Axioplan; Zeiss). As slide-mounting medium we 140 used $70 \%$ ethanol, because other commonly used solutions like lactic acid may change stable 
141 isotope compositions. We used keys by Hopkin (2007), Fjellberg (1998, 2007) and Weigmann 142 (2006).

143

144 Stable isotope analysis

145 The four most abundant Collembola taxa (I. caerulea, I. maculatus, O. villosa and Mesaphorura 146 sp.) and the two most abundant oribatid mite species (Scheloribates laevigatus and Tectocepheus 147 sarekensis) were chosen for stable isotope analysis. To achieve at least $10 \mu \mathrm{g}$ of animal dry 148 weight per sample we used 1 - 14 individuals per sample. To have at least three values for every 149 species $\mathrm{x}$ drought $\mathrm{x}$ farming system combination we included pseudoreplicates in plots with 150 many individuals (Table 1). Animals were weighed into tin capsules and dried at $60^{\circ} \mathrm{C}$ for $24 \mathrm{~h}$. 151 Wheat from every plot was dried, milled and weighed into tin capsules (ca. $1 \mathrm{mg}$ per sample). 152 Stable isotope analysis of animals was done with a coupled setup of an elemental analyzer 153 (Eurovector, Milano, Italy) and a mass spectrometer (Delta Vplus, Thermo Fisher Scientific, 154 Bremen, Germany) adjusted for small sample sizes (Langel and Dyckmans 2014). Stable isotope 155 analysis of wheat was done with another set of elemental analyzer and mass spectrometer (Flash 2000 elemental analyser coupled to a DELTA Plus XP continuous-flow IRMS via a ConFlo IV interface, Thermo Fisher Scientific, Bremen, Germany). Variations in stable isotope ratios including baseline correction were expressed using the delta notation with $\Delta X=\left(\mathrm{R}_{\text {SAMPLE }} / \mathrm{R}_{\text {STANDARD }}\right) / \mathrm{R}_{\text {STANDARD }} \mathrm{X} 1000$ with $X$ representing the target isotope $\left({ }^{13} \mathrm{C},{ }^{15} \mathrm{~N}\right)$, and $R_{\text {SAMPLE }}$ and $R_{\text {STANDARD }}$ the ratios of the heavy to the light isotope $\left({ }^{13} \mathrm{C} /{ }^{12} \mathrm{C},{ }^{15} \mathrm{~N} /{ }^{14} \mathrm{~N}\right)$ of the sample and the standard, respectively. As standard for ${ }^{13} \mathrm{C}$ PeeDee Belemnite and for ${ }^{15} \mathrm{~N}$ atmospheric air was used (Coplen et al. 2002). Acetanilide was used for internal calibration.

Statistical analyses

All statistical analyses were done in R version 4.0.2 (R Development Core Team 2020). We calculated mean abundances for each species. Abundance data were analyzed with linear mixed effects models (LMMs) for individual species with farming system and drought as fixed factors, and field as random factor using the package nlme (Pinheiro et al. 2021). Stable isotope data were baseline corrected using wheat stable isotope values of the respective plot and analyzed with a LMM with farming system and drought as fixed factors, and plot as random factor to account for differences in sample size. Because the interaction species $\mathrm{x}$ 
172 drought as well as species $\mathrm{x}$ farming system was significant (Table 2), we ran individual LMMs

173 for each species to detect species-specific effects of drought and farming system. In these models

174 we again included drought and farming system and their interaction as fixed factors, and plot as

175 random factor.

176 The size of the isotopic niches of each species in the two farming systems and in the two drought

177 treatments was calculated and visualized with the R package SIBER (Jackson et al. 2011).

178 Standard ellipse areas with a correction for small sample sizes (SEAc) based on maximum

179 likelihood were estimated and used to visualize isotopic niches of all species in the two farming

180 systems and drought treatments. To compare isotopic niche widths between farming systems and

181 drought treatments within species, Bayesian multivariate normal distributions were fitted to the

182 two levels of the factor farming system and drought, with prior settings of length, number and

183 iterations of sampling chains, and distribution parameters as recommended by Jackson (2019).

184 Based on these probability distributions Bayesian standard ellipse areas were calculated and

185 plotted using the function siberDensityPlot() including 50\%, 75\% and 95\% credible intervals.

186 For statistical comparison of isotopic niche sizes of the farming systems and the drought

187 treatments for individual species, we compared probability distributions from the Bayesian

188 standard ellipses with 95\% credible intervals.

189

190 Results

191 Soil characteristics

192 Water holding capacity, $\mathrm{pH}$ and total carbon were higher in organically compared to

193 conventionally managed fields (Supplementary Table 1). Total carbon at our study site is

194 equivalent to total organic carbon, because the soil is free of carbonates. Soil water content was

195 decreased by experimental drought by $4.23 \%$ and was generally higher in organically compared

196 to conventionally managed fields (Supplementary Figure 1; see Meyer et al. 2021).

197

198 Abundance

199 Based on their mean abundance the six mesofauna taxa could be separated into two groups of

200 high and low abundance with abundances of the former being 23 to 73 times higher than that of

201 the latter. Highly abundant taxa included S. laevigatus, T. sarekensis and Mesaphorura sp.

202 (overall average of $7648 \pm 1528,7392 \pm 1286$ and $5312 \pm 1734$ ind. $\mathrm{m}^{-2}$, respectively; mean \pm

203 SE). Species with low abundances included I. caerulea, I. maculatus and O. villosa (106.8 \pm 
$20432.7,105.0 \pm 29.3$ and $227.5 \pm 49.8$ ind. $\mathrm{m}^{-2}$, resepectively). Generally, abundances of individual 205 species did not change significantly with drought treatment or farming system (Table 3, 206 Supplementary Figure 2).

207

208 Isotope values

209 Mean stable isotope values were significantly different between species, spanning over two $\delta$ 210 units for ${ }^{13} \mathrm{C}$ and over four $\delta$ units for ${ }^{15} \mathrm{~N}$ (Figure 1, Table 2). The $\Delta \Delta^{13} \mathrm{C}$ values of the two 211 oribatid mite species were three to four $\delta$ units higher than those of the three Collembola species. 212 Mean $\Delta{ }^{15} \mathrm{~N}$ values spanned over four $\delta$ units with the values of S. laevigatus exceeding those of 213 the other species by three to four $\delta$ units.

214 The $\Delta^{13} \mathrm{C}$ but not $\Delta^{15} \mathrm{~N}$ values differed significantly among the studied mesofauna species 215 between the drought treatments (Table 2), with this pattern being driven by a significant 216 reduction in the $\Delta^{13} \mathrm{C}$ values of $S$. laevigatus under drought; $\Delta{ }^{13} \mathrm{C}$ values of the other species 217 were not significantly affected by drought (Figure 2, Table 3). By contrast, both $\Delta^{13} \mathrm{C}$ and $\Delta^{15} \mathrm{~N}$ 218 values of mesofauna species varied significantly with farming system (significant species $\times$ 219 farming system interaction; Table 2). In organically managed fields the $\Delta^{13} \mathrm{C}$ value of $T$. 220 sarekensis and the $\Delta^{15} \mathrm{~N}$ values of I. caerulea and $O$. villos a significantly exceeded those in 221 conventionally managed fields (Figure 3, Table 3).

222 Drought significantly reduced the isotopic niche width of $S$. laevigatus $(P=0.016)$, I. caerulea $223(P=0.003)$ and I. maculatus $(\mathrm{P}=0.032)$ (Figure 4$)$, with isotopic niches of $S$. laevigatus partly 224 overlapping between the two drought treatments, whereas in I. caerulea and I. maculatus they 225 overlapped in full (Figure 5). Further, the isotopic niche space of I. caerulea and I. maculatus 226 was significantly smaller in organically compared to conventionally managed fields, with 227 isotopic niches of I. caerulea partly overlapping between the two farming systems, whereas 228 those of I. maculatus overlapped in full (Figure 6).

229

230

231 The species studied were selected based on two criteria: sufficiently high abundance combined 232 with sufficiently high biomass for stable isotope analyses, and therefore can be considered as the 233 most important Collembola and Oribatida species of the system regarding energy flux and 234 functioning. Interestingly, the farming system and the experimental drought did not affect the 
235 abundances of the studied species significantly, but affected their trophic niches as indicated by 236 stable isotope analyses.

237

238 Trophic positions

239 Overall, stable isotope values of the studied microarthropods spanned two $\delta$ units in ${ }^{13} \mathrm{C}$ and four $240 \delta$ units in ${ }^{15} \mathrm{~N}$, indicating the utilization of different $\mathrm{C}$ resources and the representation of at least 241 two trophic levels, assuming an enrichment of about $3 \delta$ units per trophic level (Post 2002).

242 Based on the $\Delta^{13} \mathrm{C}$ and $\Delta^{15} \mathrm{~N}$ values of the individual species, the studied taxa can be separated 243 into three groups, the three Collembola species, the Oribatida species T. sarekensis and the 244 Oribatida species S. laevigatus.

245 The three Collembola species I. caerulea, I. maculatus and O. villosa had $\Delta^{15} \mathrm{~N}$ values close to 246 zero, indicating they are closely linked to wheat plants and suggesting that they live as primary 247 decomposers that are little enriched in ${ }^{15} \mathrm{~N}(-0.05 \%$, $-0.12 \%$, $1.23 \%$, respectively $)$. Earlier 248 studies also found large epi- and hemiedaphic Collembola species, such as the ones we studied, 249 to predominantly feed on plant-derived resources in both agroecosystems and forests (Pollierer et 250 al. 2009; Birkhofer et al. 2016; Potapov et al. 2016). Ngosong et al. (2009) further found plant 251 rather than fungal resources to be incorporated by Collembola in agricultural systems, and results 252 of the study of $\mathrm{Li}$ et al. (2020) suggest that root-derived carbon is a major resource.

253 Isotope values of ${ }^{13} \mathrm{C}$ of both Oribatida species exceeded those of the three Collembola species 254 by one to two $\delta$ units, indicating that both are linked to resources enriched in ${ }^{13} \mathrm{C}$. However, their $255 \Delta^{15} \mathrm{~N}$ values indicated that they occupy different trophic levels with $T$. sarekensis living as 256 primary decomposer and $S$. laevigatus as secondary decomposer or predator, similar to what has 257 been previously suggested (Schneider et al. 2004; Haynert et al. 2017). The average $\delta^{13} \mathrm{C}$ value 258 of $T$. sarekensis being $4.55 \%$ higher than plant litter indicates that $T$. sarekensis is linked to 259 older carbon resources, probably soil organic matter in deeper soil layers (Potapov et al. 2019).

260 The average $\delta^{15} \mathrm{~N}$ value of $S$. laevigatus being $3.77 \%$ higher than that of plant litter indicates a 261 mixed diet consisting of mainly microorganisms, but in part also microbial feeders such as 262 nematodes.

263

264 Farming system 
265 Our second hypothesis was partly supported by the significantly higher isotope values of $T$. 266 sarekensis, I. caerulea and $O$. villosa in the organic compared to the conventional farming 267 system. However, we did not find differences for the other taxa, which is in line with earlier 268 studies comparing different agricultural systems (Haubert et al. 2009; Birkhofer et al. 2011; 269 Lagerlöf et al. 2017). The higher isotope values of T. sarekensis, I. caerulea and O. villosa in the 270 organic farming system likely are related to the higher soil organic carbon content that was found 271 in this system. The higher $\Delta^{13} \mathrm{C}$ values of $T$. sarekensis in organically compared to 272 conventionally managed fields indicate that they more intensively feed on old carbon resources 273 in the organic system, which is richer in soil organic matter due to long-term input of farmyard 274 manure and compost (Mäder et al. 2002). In I. caerulea and $O$. villosa $\Delta^{15} \mathrm{~N}$ values were higher 275 in organically compared to conventionally managed fields, pointing to a higher proportion of 276 microorganisms in their diet in the organic system. In fact, previous studies conducted in the 277 same long-term experiment as the present study found higher microbial biomass in the 278 organically than the conventionally managed fields indicating a higher availability of microbes 279 as food resource (Esperschütz et al. 2007; Fließbach et al. 2007). This is likely to be a 280 consequence of higher soil water content and soil organic carbon in the organically managed 281 fields. This effect might further be enhanced by higher $\delta^{15} \mathrm{~N}$ values of the organic fertilizer 282 (farmyard manure) compared to the inorganic fertilizer in the conventional system (Birkhofer et 283 al. 2011). Higher stable isotope values in the organic system may additionally be caused by 284 stable isotope enrichment of soil organic matter due to stronger internal nutrient cycling (Vervaet 285 et al. 2002; Hobbie and Ouimette 2009).

286 Besides the comparison of mean stable isotope values, additional information on trophic shifts of 287 species can be obtained by comparing trophic niche width and trophic niche space (Behan288 Pelletier 1999; Bearhop et al. 2004). Our hypothesis on changes in trophic niche width with 289 farming system was based on the assumption that in less disturbed habitats consumers would 290 have a greater range of potentially available food resources, from which species could select 291 according to their preferences. By contrast, in more severely disturbed systems, preferred 292 resources may not be available, forcing consumers to feed on a wider range of resources 293 resulting in broader trophic niches. Our data support this hypothesis only partly for the two 294 farming systems and, interestingly, in some species showed the opposite pattern for the drought 295 treatment (see below). Variations in $\Delta^{13} \mathrm{C}$ values in I. caerulea and I. maculatus were small in the 
296 organic farming system indicating a diet consisting of fresh litter or root exudates, whereas in the 297 conventional farming system diets varied more widely. This suggests the utilization of a wider 298 range of resources including old litter and microorganisms resulting in increased $\delta^{13} \mathrm{C}$ values 299 (Potapov et al. 2019) or algae resulting in decreased $\delta^{13} \mathrm{C}$ values (Tozer et al. 2005). In the 300 conventional system, the amount of litter input is low and limited to plant residues from the crop 301 plant, i.e., mainly roots, whereas in the organic system plant residues in the organic fertilizer 302 provide additional food resources. Further, the amount of rhizodeposits in the conventional 303 system is likely to be lower than in the organic system, thereby providing fewer resources to the 304 belowground food web (Jones et al. 2001; Li et al. 2016; Wang et al. 2016). The lower 305 availability of preferred food resources in the conventional compared to the organic farming 306 system may force soil invertebrates to broaden their trophic niche. Further, in the conventional 307 farming system more algae may be present due to the scarcity of weeds (Meyer et al. 2021) 308 providing additional food resources that are not equally available in organic farming systems.

Drought

311 Drought significantly decreased soil moisture in both farming systems. However, contradicting 312 our second hypothesis, drought did not affect stable isotope values of most taxa and there was no 313 significant interaction with farming system. Only $S$. laevigatus had lower $\Delta^{13} \mathrm{C}$ and constantly 314 high $\Delta^{15} \mathrm{~N}$ values in the drought treatment indicating prey switching. Assuming that $S$.

315 laevigatus, at least in part, feeds on nematodes, this might represent a switch from microbial316 feeding to plant-feeding nematodes, due to microbial-feeding nematodes being heavily stressed 317 under dry conditions due to reduced microbial activity (Kundel et al. 2020). In contrast to 318 conventional farming and contrasting our second hypothesis, drought decreased the trophic niche 319 width in some species (S. laevigatus, I. caerulea and I. maculatus). For S. laevigatus this was 320 caused by lower $\Delta^{13} \mathrm{C}$ values in the drought treatment, probably due to prey switching (see 321 above). In the two Collembola species the decreased trophic niche width was due to decreased 322 variation in $\Delta^{13} \mathrm{C}$ values, but not lower mean $\Delta^{13} \mathrm{C}$ values, indicating more restricted 323 consumption of plant-derived resources rather than algae and microorganisms. Accessibility of 324 algae and microorganisms is likely to decrease at low soil moisture, whereas the availability of 325 (higher) plant-derived resources may be less affected. In fact, plant-related variables, including 326 root biomass, shoot biomass and grain yield, did not differ between the drought treatments in this 
327 experiment (Kundel et al. 2020). For I. caerulea, additionally, the smaller variation in $\Delta^{15} \mathrm{~N}$

328 values, but no changes in mean $\Delta^{15} \mathrm{~N}$ values, in the drought treatment supports the conclusion of 329 narrower trophic niches due to more pronounced feeding on plant material.

330

331

332

333

334

335

336

337

338

339

340

341

342

343

344

345

346

347

348

349

350

351

352

353

354

355

356

357

358

\section{Conclusions}

Drought did not significantly affect mean stable isotope values of most of the studied mesofauna species, but trophic niche width and space changed significantly, highlighting the relevance of these trophic niche characteristics for tracking effects of changes in environmental factors on soil food webs. Our results provide further evidence that in agricultural fields both plant litter and root-derived carbon play an important role as food resource for soil microarthropods. Overall, our data indicate that short-term drought as well as organic farming reduces the diversity of the resources used by soil microarthropods and favors the use of plants as basal resource for Collembola and Oribatida instead of microorganisms and algae. At the same time, the abundances of Collembola and Oribatida were not affected, suggesting that a flexible usage of resources may buffer negative effects of drought conditions on microarthropod communities in agricultural fields.

\section{Acknowledgements}

We thank Guido Humpert for help with field work and Barbara Wozniak for help with sorting of animals. We gratefully acknowledge support by the Open Access Publication Funds of the University Göttingen. We further thank the Physiological Plant Ecology Group led by Ansgar Kahmen at the University of Basel for the measurement of stable isotopes in wheat plants.

\section{References}

Adams TS, Sterner RW (2000) The effect of dietary nitrogen content on trophic level 15N enrichment. Limnol Oceanogr 45:601-607. https://doi.org/10.4319/lo.2000.45.3.0601

Barreto C, Branfireun BA, McLaughlin JW, Lindo Z (2021) Responses of oribatid mites to warming in boreal peatlands depend on fen type. Pedobiologia 89:150772. https://doi.org/10.1016/j.pedobi.2021.150772

Bearhop S, Adams CE, Waldron S, et al (2004) Determining trophic niche width: A novel approach using stable isotope analysis. J Anim Ecol 73:1007-1012. https://doi.org/10.1111/j.0021-8790.2004.00861.x 
359

360

361

362

363

364

365

366

367

368

369

370

371

372

373

374

375

376

377

378

379

380

381

382

383

384

385

386

387

388

389

Behan-Pelletier VM (1999) Oribatid mite biodiversity in agroecosystems: role for bioindication. Agric Ecosyst Environ 74:411-423. https://doi.org/10.1016/S0167-8809(99)00046-8

Birkhofer K, Bezemer TM, Bloem J, et al (2008) Long-term organic farming fosters below and aboveground biota: Implications for soil quality, biological control and productivity. Soil Biol Biochem 40:2297-2308. https://doi.org/10.1016/j.soilbio.2008.05.007

Birkhofer K, Dietrich C, John K, et al (2016) Regional conditions and land-use alter the potential contribution of soil arthropods to ecosystem services in Grasslands. Front Ecol Evol 3:. https://doi.org/10.3389/fevo.2015.00150

Birkhofer K, Fließbach A, Wise DH, Scheu S (2011) Arthropod food webs in organic and conventional wheat farming systems of an agricultural long-term experiment: a stable isotope approach. Agric For Entomol 13:197-204. https://doi.org/10.1111/j.14619563.2010.00511.x

Birkhofer K, Smith HG, Weisser WW, et al (2015) Land-use effects on the functional distinctness of arthropod communities. Ecography (Cop) 38:889-900

Blankinship JC, Niklaus PA, Hungate BA (2011) A meta-analysis of responses of soil biota to global change. Oecologia 553-565. https://doi.org/10.1007/s00442-011-1909-0

Chahartaghi M, Langel R, Scheu S, Ruess L (2005) Feeding guilds in Collembola based on nitrogen stable isotope ratios. Soil Biol Biochem 37:1718-1725. https://doi.org/10.1016/j.soilbio.2005.02.006

Coplen TB, Böhlke JK, De Bièvre P, et al (2002) Isotope-abundance variations of selected elements (IUPAC technical report). Pure Appl Chem 74:1987-2017. https://doi.org/10.1351/pac200274101987

EEA (2017) Climate change, impacts and vulnerability in Europe 2016. Publications Office of the European Union, Luxembourg

Erktan A, Or D, Scheu S (2020) The physical structure of soil: Determinant and consequence of trophic interactions. Soil Biol Biochem 148:107876. https://doi.org/10.1016/j.soilbio.2020.107876

Esperschütz J, Gattinger A, Mäder P, et al (2007) Response of soil microbial biomass and community structures to conventional and organic farming systems under identical crop rotations. FEMS Microbiol Ecol 61:26-37. https://doi.org/10.1111/j.15746941.2007.00318.x 
390 Fjellberg A (1998) The Collembola of Fennoscandia and Denmark, Part I: Poduromorpha 391 Fauna Entomologica Scandinavica 35. Brill, Leiden, Boston, Köln

392 Fjellberg A (2007) The Collembola of Fennoscandia and Denmark, Part II: Entomobryomorpha 393 and Symphypleona - Fauna Entomologica Scandinavica 42. Brill, Leiden, Boston 394 Fließbach A, Oberholzer HR, Gunst L, Mäder P (2007) Soil organic matter and biological soil 395 396

397 398 399 400 401 402 403 404 405 406 407 408 409 410 411 412 413 414 415 416 417 418 419 420 quality indicators after 21 years of organic and conventional farming. Agric Ecosyst Environ 118:273-284. https://doi.org/10.1016/j.agee.2006.05.022

Frampton GK, Van den Brink PJ, Gould PJLL (2000) Effects of spring precipitation on a temperate arable collembolan community analysed using Principal Response Curves. Appl Soil Ecol 14:231-248. https://doi.org/10.1016/S0929-1393(00)00051-2

Geng SM, Yan DH, Zhang TX, et al (2015) Effects of drought stress on agriculture soil. Nat Hazards 75:1997-2011. https://doi.org/10.1007/s11069-014-1409-8

Giller PS (1996) The diversity of soil communities, the "poor man's tropical rainforest." Biodivers Conserv 5:135-168. https://doi.org/10.1007/BF00055827

Haubert D, Birkhofer K, Fließbach A, et al (2009) Trophic structure and major trophic links in conventional versus organic farming systems as indicated by carbon stable isotope ratios of fatty acids. Oikos 118:1579-1589. https://doi.org/10.1111/j.1600-0706.2009.17587.x

Haynert K, Kiggen M, Klarner B, et al (2017) The structure of salt marsh soil mesofauna food webs - The prevalence of disturbance. PLoS One 12:1-20. https://doi.org/10.1371/journal.pone.0189645

Hines J, van der Putten WH, De Deyn GB, et al (2015) Towards an integration of biodiversityecosystem functioning and food web theory to evaluate relationships between multiple ecosystem services. In: Advances in Ecological Research, 1st edn. Elsevier Ltd., pp 161199

Hobbie EA, Ouimette AP (2009) Controls of nitrogen isotope patterns in soil profiles. Biogeochemistry 95:355-371. https://doi.org/10.1007/s10533-009-9328-6

Holmstrup M, Sørensen JG, Schmidt IK, et al (2013) Soil microarthropods are only weakly impacted after 13 years of repeated drought treatment in wet and dry heathland soils. Soil Biol Biochem 66:110-118. https://doi.org/10.1016/j.soilbio.2013.06.023

Hopkin SP (2007) A key to the springtails (Collembola) of Britain and Ireland. FSC Publications, Shrewsbury 
421 Jackson AL (2019) SIBER introduction and guide. 1-13

422 Jackson AL, Inger R, Parnell AC, Bearhop S (2011) Comparing isotopic niche widths among 423 and within communities: SIBER - Stable Isotope Bayesian Ellipses in R. J Anim Ecol 424 80:595-602. https://doi.org/10.1111/j.1365-2656.2011.01806.x

425 Jaleel CA, Manivannan P, Wahid A, et al (2009) Drought stress in plants: A review on 426 morphological characteristics and pigments composition. Int J Agric Biol 11:100-105 427 Jones VP, Westcott DM, Finson NN, Nishimoto RK (2001) Relationship Between Community 428 Structure and Southern Green Stink Bug (Heteroptera: Pentatomidae) Damage in 429 430 Macadamia Nuts. Environ Entomol 30:1028-1035. https://doi.org/10.1603/0046-225X30.6.1028

Kardol, P., Reynolds, W. N., Norby, R. J., \& Classen, A. T. (2011). Climate change effects on soil microarthropod abundance and community structure. Applied Soil Ecology, 47, 37- 44. https://doi.org/10.1016/j. apsoil.2010.11.001

Kempson D, Lloyd M, Ghelardi R (1963) A new extractor for woodland litter. Pedobiologia (Jena) 3:1-21

Korotkevich AY, Potapov AM, Tiunov A V., Kuznetsova NA (2018) Collapse of trophic-niche structure in belowground communities under anthropogenic disturbance. Ecosphere 9:. https://doi.org/10.1002/ecs2.2528

Krab EJ, Aerts R, Berg MP, et al (2014) Northern peatland Collembola communities unaffected by three summers of simulated extreme precipitation. Appl Soil Ecol 79:70-76. https://doi.org/10.1016/j.apsoil.2014.03.007

Krause A, Sandmann D, Bluhm SL, et al (2019) Shift in trophic niches of soil microarthropods with conversion of tropical rainforest into plantations as indicated by stable isotopes (15N, 13C). PLoS One 14:1-14. https://doi.org/10.1371/journal.pone.0224520

Krause H-M, Fliessbach A, Mayer J, Mäder P (2020) Implementation and management of the DOK long-term system comparison trial. In: Bhullar GS, Riar A (eds) Long-Term Farming Systems Research. Academic Press, pp 37-51

Kundel D, Bodenhausen N, Jørgensen HB, et al (2020) Effects of simulated drought on biological soil quality, microbial diversity and yields under long-term conventional and organic agriculture. FEMS Microbiol Ecol 96:1-16. https://doi.org/10.1093/femsec/fiaa205 Kundel D, Meyer S, Birkhofer H, et al (2018) Design and manual to construct rainout-shelters 
452

453

454

455

456

457

458

459

460

461

462

463

464

465

466

467

468

469

470

471

472

473

474

475

476

477

478

479

480

481

482

for climate change experiments in agroecosystems. Front Environ Sci 6:1-9. https://doi.org/10.3389/fenvs.2018.00014

Lagerlöf J, Maribie C, Muturi John J (2017) Trophic interactions among soil arthropods in contrasting land-use systems in Kenya, studied with stable isotopes. Eur J Soil Biol 79:3139. https://doi.org/10.1016/j.ejsobi.2017.01.002

Langel R, Dyckmans J (2014) Combined 13C and 15N isotope analysis on small samples using a near-conventional elemental analyzer/isotope ratio mass spectrometer setup. Rapid Commun Mass Spectrom 28:1019-1022. https://doi.org/10.1002/rcm.6878

Li Y, Wang J, Pan F, Chapman SJ (2016) Soil nitrogen availability alters rhizodeposition carbon flux into the soil microbial community. J Soils Sediments 1472-1480. https://doi.org/10.1007/s11368-015-1337-6

Li Z, Scheunemann N, Potapov AM, et al (2020) Incorporation of root-derived carbon into soil microarthropods varies between cropping systems. Biol Fertil Soils 839-851. https://doi.org/10.1007/s00374-020-01467-8

Lotter DW, Seidel R, Liebhardt W (2003) The performance of organic and conventional cropping systems in an extreme climate year. Am J Altern Agric 18:146-154. https://doi.org/10.1079/AJAA200345

Macfadyen A (1961) Improved Funnel-Type Extractors for Soil Arthropods. J Anim Ecol 30:171. https://doi.org/10.2307/2120

MacFadyen S, Gibson R, Polaszek A, et al (2009) Do differences in food web structure between organic and conventional farms affect the ecosystem service of pest control? Ecol Lett 12:229-238. https://doi.org/10.1111/j.1461-0248.2008.01279.x

Mäder P, Fließbach A, Dubois D, et al (2002) Soil fertility and biodiversity in organic farming. Science (80- ) 296:1694-1697. https://doi.org/10.1126/science.1071148

Melguizo-Ruiz N, Jiménez-Navarro G, Zieger SL, et al (2017) Complex effects of precipitation and basal resources on the trophic ecology of soil oribatid mites: Implications for stable isotope analysis. Eur J Soil Biol 82:98-107. https://doi.org/10.1016/j.ejsobi.2017.08.008

Meyer S, Kundel D, Birkhofer K, et al (2021) Soil microarthropods respond differently to simulated drought in organic and conventional farming systems. Ecol Evol 10369-10380. https://doi.org/10.1002/ece3.7839

Ngosong C, Raupp J, Scheu S, Ruess L (2009) Low importance for a fungal based food web in 
483

484

485

486

487

488

489

490

491

492

493

494

495

496

497

498

499

500

501

502

503

504

505

506

507

508

509

510

511

512

513

arable soils under mineral and organic fertilization indicated by Collembola grazers. Soil Biol Biochem 41:2308-2317. https://doi.org/10.1016/j.soilbio.2009.08.015

Oelbermann K, Scheu S (2002) Stable isotope enrichment ( $\delta 15 \mathrm{~N}$ and $\delta 13 \mathrm{C})$ in a generalist predator (Pardosa lugubris, Araneae: Lycosidae): Effects of prey quality. Oecologia 130:337-344. https://doi.org/10.1007/s004420100813

Pinheiro J, Bates D, DebRoy S, Sarkar D, R Core Team (2021) nlme: Linear and Nonlinear Mixed Effects Models. R package version 3.1-153, https://CRAN.Rproject.org $/$ package $=$ nlme

Pollierer MM, Langel R, Scheu S, Maraun M (2009) Compartmentalization of the soil animal food web as indicated by dual analysis of stable isotope ratios (15N/14N and 13C/12C). Soil Biol Biochem 41:1221-1226. https://doi.org/10.1016/j.soilbio.2009.03.002

Pollierer MM, Scheu S (2021) Stable isotopes of amino acids indicate that soil decomposer microarthropods predominantly feed on saprotrophic fungi. Ecosphere 12:. https://doi.org/10.1002/ecs2.3425

Post DM (2002) Using Stable Isotopes to Estimate Trophic Position: Models, Methods, and Assumptions. Ecology 83:703. https://doi.org/10.2307/3071875

Potapov AA, Semenina EE, Korotkevich AY, et al (2016) Connecting taxonomy and ecology: trophic niches of collembolans as related to taxonomic identity and life forms. Soil Biol Biochem 101:20-31. https://doi.org/10.1016/j.soilbio.2016.07.002

Potapov AM, Tiunov A V., Scheu S (2019) Uncovering trophic positions and food resources of soil animals using bulk natural stable isotope composition. Biol Rev 94:37-59. https://doi.org/10.1111/brv.12434

R Development Core Team R (2020) R: A language and environment for statistical computing. Available online at: https://www.r-project.org/

Samaniego L, Thober S, Kumar R, et al (2018) Anthropogenic warming exacerbates European soil moisture droughts. Nat Clim Chang 8:421-426. https://doi.org/10.1038/s41558-0180138-5

Scheu S (1998) The soil food web: structure and perspectives. Eur J Soil Biol 38:147-156. https://doi.org/10.1016/S1164-5563(01)01117-7

Scheu S, Falca M (2000) International Association for Ecology The Soil Food Web of Two Beech Forests ( Fagus sylvatica ) of Contrasting Humus Type : Stable Isotope Analysis of a 
514 Macro- and a Mesofauna-Dominated Community Published by : Springer in cooperation

515 with International. Oecologia 123:285-296

516 Scheunemann N, Digel C, Scheu S, Butenschoen O (2015) Roots rather than shoot residues drive

517 soil arthropod communities of arable fields. Oecologia 179:1135-1145.

$518 \quad$ https://doi.org/10.1007/s00442-015-3415-2

519 Schneider K, Migge S, Norton RA, et al (2004) Trophic niche differentiation in soil

520 microarthropods (Oribatida, Acari): evidence from stable isotope ratios (15N/14N). Soil

521 Biol Biochem 36:1769-1774. https://doi.org/10.1016/j.soilbio.2004.04.033

522 Spinoni J, Naumann G, Vogt J (2015) Spatial patterns of European droughts under a moderate 523 emission scenario. Adv Sci Res 12:179-186. https://doi.org/10.5194/asr-12-179-2015

524 Susanti WI, Widyastuti R, Scheu S, Potapov A (2021) Trophic niche differentiation and

525 utilisation of food resources in Collembola is altered by rainforest conversion to plantation

$526 \quad$ systems. PeerJ 9:1-18. https://doi.org/10.7717/peerj.10971

527 Tozer WC, Hackell D, Miers DB, Silvester WB (2005) Extreme isotopic depletion of nitrogen in

528 New Zealand lithophytes and epiphytes; the result of diffusive uptake of atmospheric

529 ammonia? Oecologia 144:628-635. https://doi.org/10.1007/s00442-005-0098-0

530 Vervaet H, Boeckx P, Unamuno V, et al (2002) Can $\delta 15 \mathrm{~N}$ profiles in forest soils predict NO3-

$531 \quad$ loss and net N mineralization rates? Biol Fertil Soils 36:143-150.

532 https://doi.org/10.1007/s00374-002-0522-0

533 Vestergård M, Dyrnum K, Michelsen A, et al (2015) Long-term multifactorial climate change 534 impacts on mesofaunal biomass and nitrogen content. 92:54-63.

535 https://doi.org/10.1016/j.apsoil.2015.03.002

536 Wang J, Chapman SJ, Yao H (2016) Incorporation of 13 C-labelled rice rhizodeposition into soil 537 microbial communities under different fertilizer applications. Appl Soil Ecol 101:11-19. $538 \quad$ https://doi.org/10.1016/j.apsoil.2016.01.010

539 Weigmann G (2006) Hornmilben (Oribatida). In: Dahl, F (ed) Die Tierwelt Deutschlands und 540 der angrenzenden Meeresteile. Bd. 76. Goecke \& Evers, Keltern

541 Zhang Q, Shao M, Jia X, Zhang C (2018) Understory Vegetation and Drought Effects on Soil 542 Aggregate Stability and Aggregate-Associated Carbon on the Loess Plateau in China. Soil Sci 543 Soc Am J 82:106-114. https://doi.org/10.2136/sssaj2017.05.0145 


\section{Figure 1}

Stable isotope values of Collembola and Oribatida

Mean ( \pm standard deviation) $\Delta^{13} \mathrm{C}$ and $\Delta^{15} \mathrm{~N}$ values of two species of Oribatida (Scheloribates laevigatus, Tectocepheus sarakensis) and three species of Collembola (Isotoma viridis, Isotomurus maculatus, Orchesella villosa); data are calibrated against stable isotope values of wheat in the respective plot. 


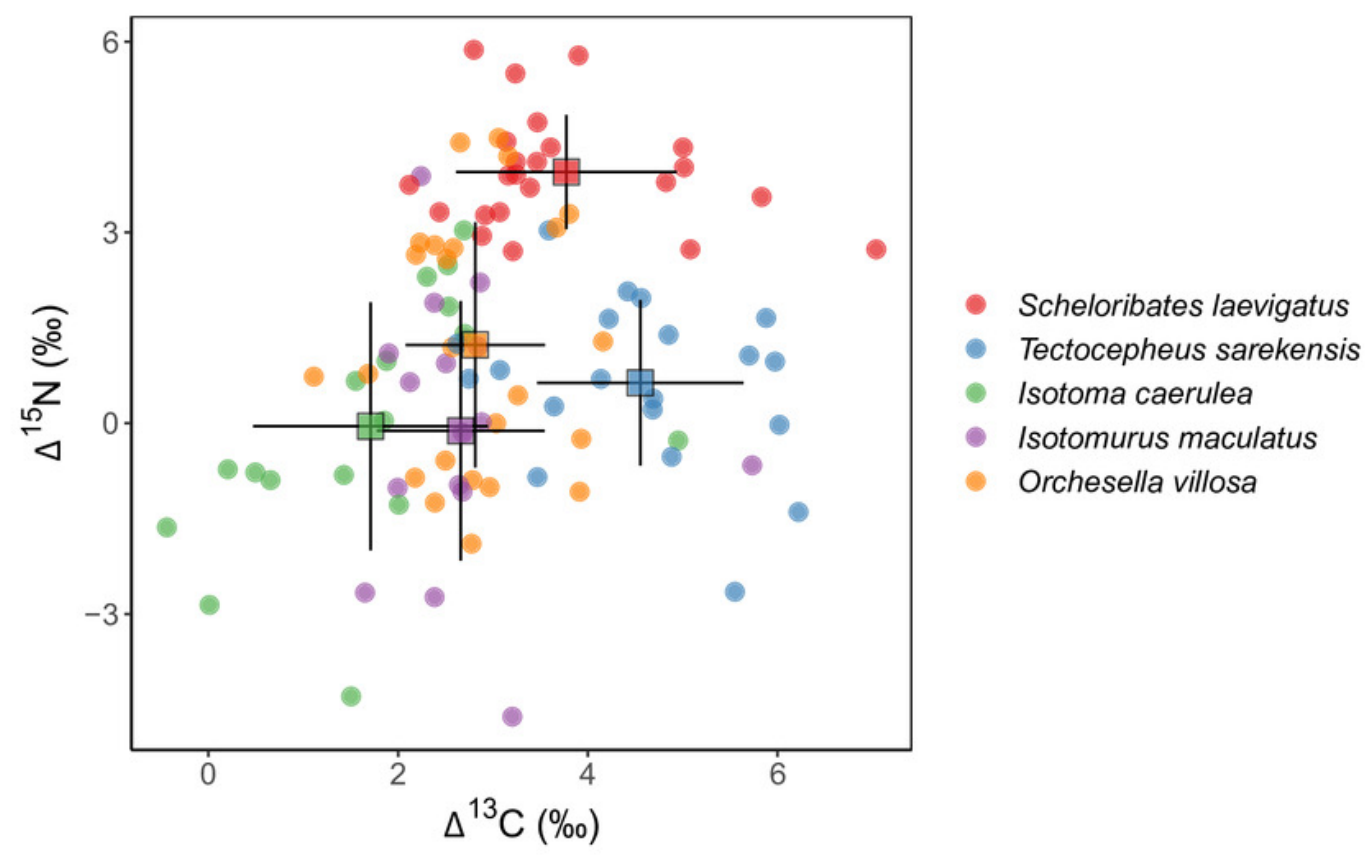


Figure 2

Stable isotope values of Collembola and Oribatida in drought and control treatment

Mean ( $\pm 95 \%$ confidence interval) $\Delta^{13} \mathrm{C}$ values in control and drought treatments (roof) for two species of Oribatida (Scheloribates laevigatus, Tectocepheus sarakensis) and four Collembola taxa (Isotoma caerulea, Isotomurus maculatus, Orchesella villosa, Mesaphorura sp.); for statistical analysis see Table 3. 


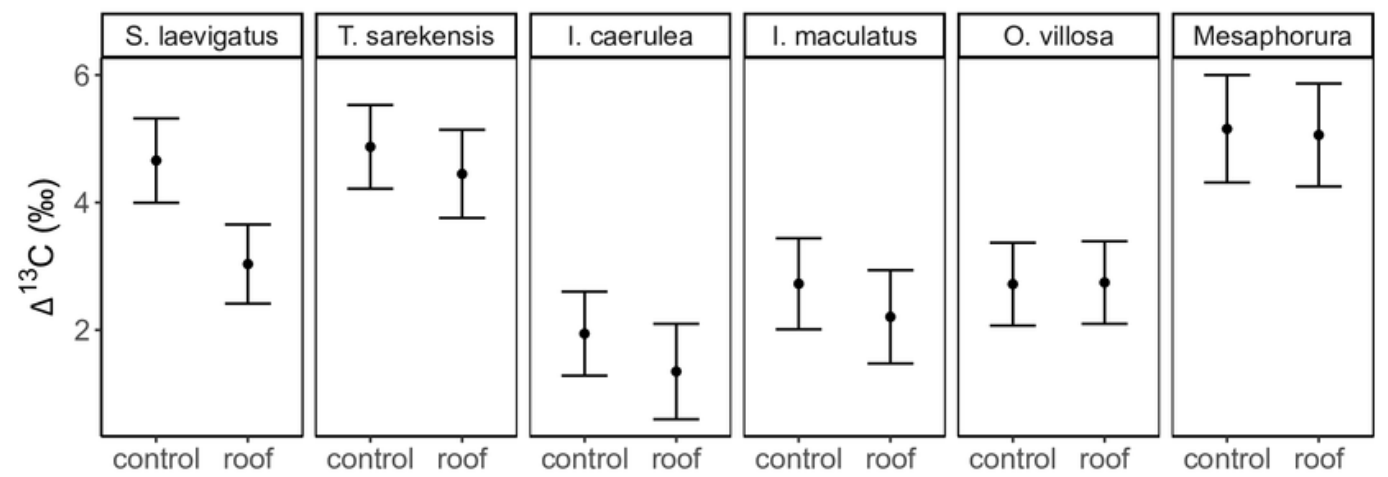




\section{Figure 3}

Stable isotope values of Collembola and Oribatida in two farming systems

Mean ( $\pm 95 \%$ confidence interval) $\Delta^{13} \mathrm{C}$ (upper panel) and $\Delta^{15} \mathrm{~N}$ values (lower panel) of two oribatid mite (Scheloribates laevigatus, Tectocepheus sarakensis) and four Collembola species (Isotoma caerulea, Isotomurus maculatus, Orchesella villosa, Mesaphorura sp.) in conventional (conv) and organic (org) farming systems; note that for Mesaphorura sp. only $\Delta^{13} \mathrm{C}$ values are shown. For statistical analysis see Table 3. 

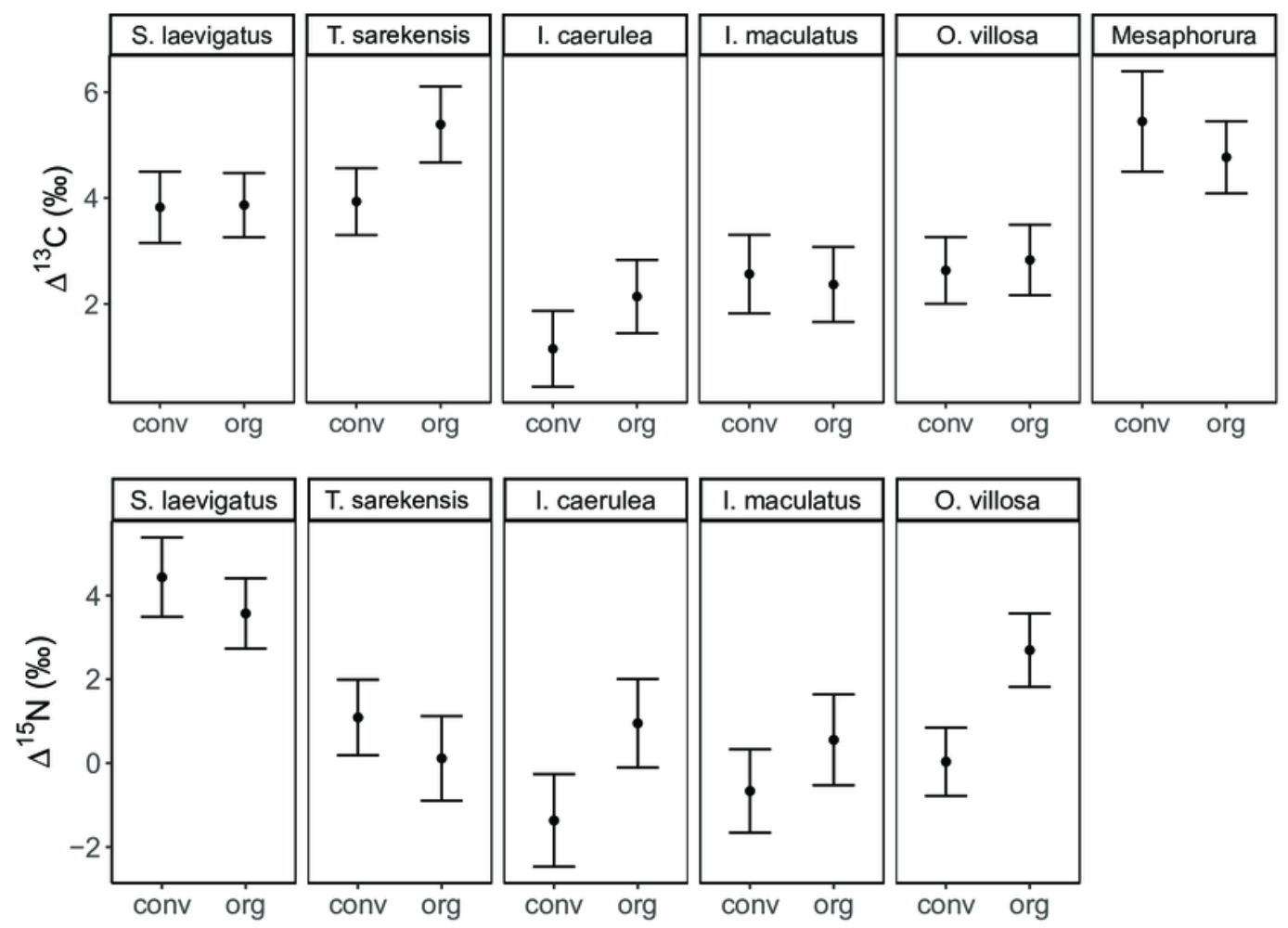


\section{Figure 4}

Isotopic niche sizes in drought and control plots and in two different farming systems

Probability distribution of the sizes of isotopic niches of five microarthropod species

(Scheloribates laevigatus, Tectocepheus sarakensis, Isotoma caerulea, Isotomurus

maculatus, Orchesella villosa) in the drought (roof) and the control treatment (upper panel), and in conventional (conv) and organic (org) farming systems (lower panel). Points show posterior estimates of the Bayesian standard ellipse area with $50 \%, 75 \%$ and $95 \%$ credible intervals (from dark to light gray). 

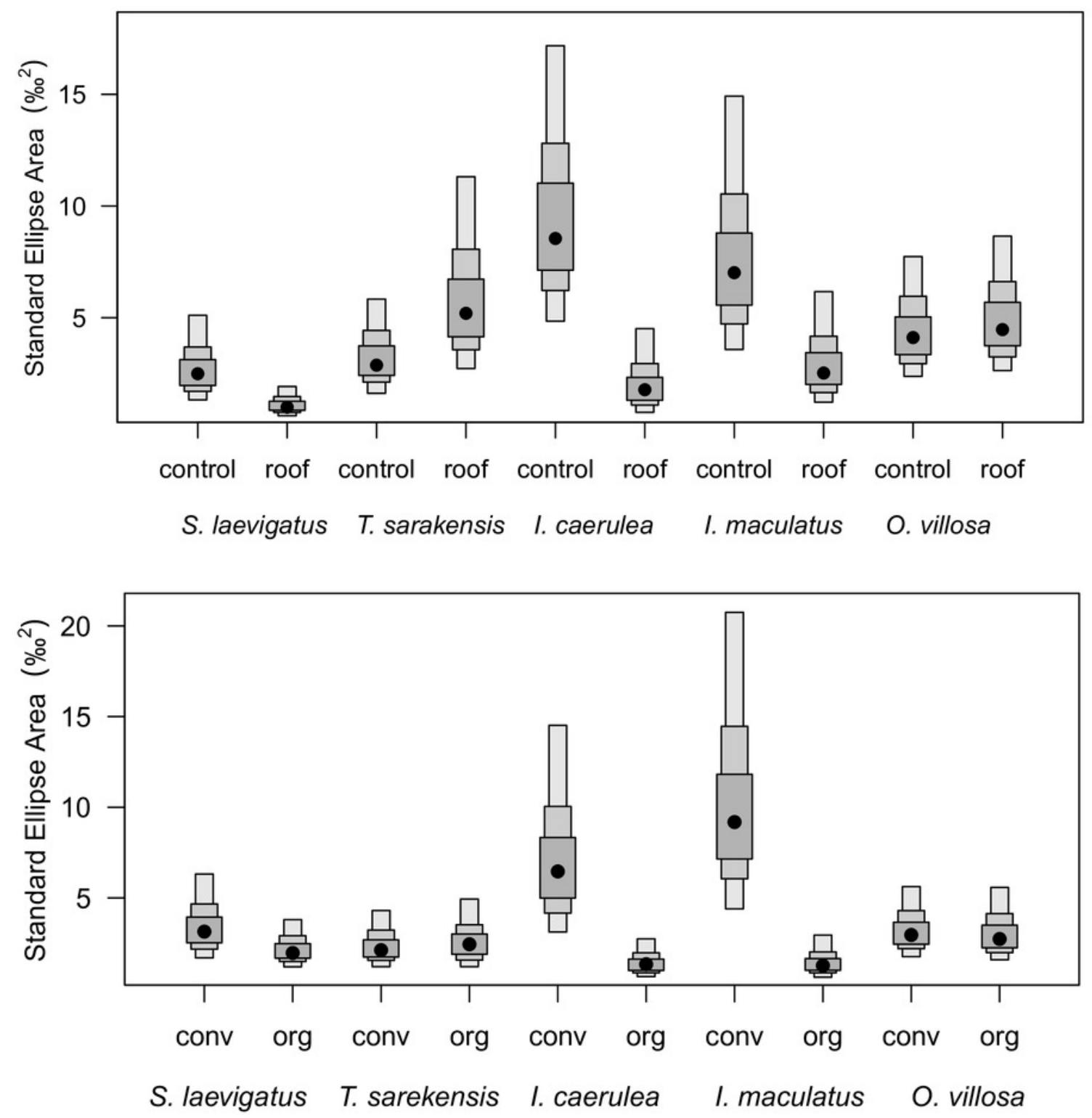


\section{Figure 5}

Isotopic niche space of Collembola and Oribatida in drought and control treatment Isotopic niche space of two oribatid mite (Scheloribates laevigatus, Tectocepheus sarakensis) and three Collembola species (Isotoma caerulea, Isotomurus maculatus, Orchesella villosa) in the drought (roof, orange) and the control (turquoise) treatment. Standardized ellipses (SEAC) account for different sample sizes between taxa and small sample sizes per taxon and encompass approximately $95 \%$ of the data; see Methods. 

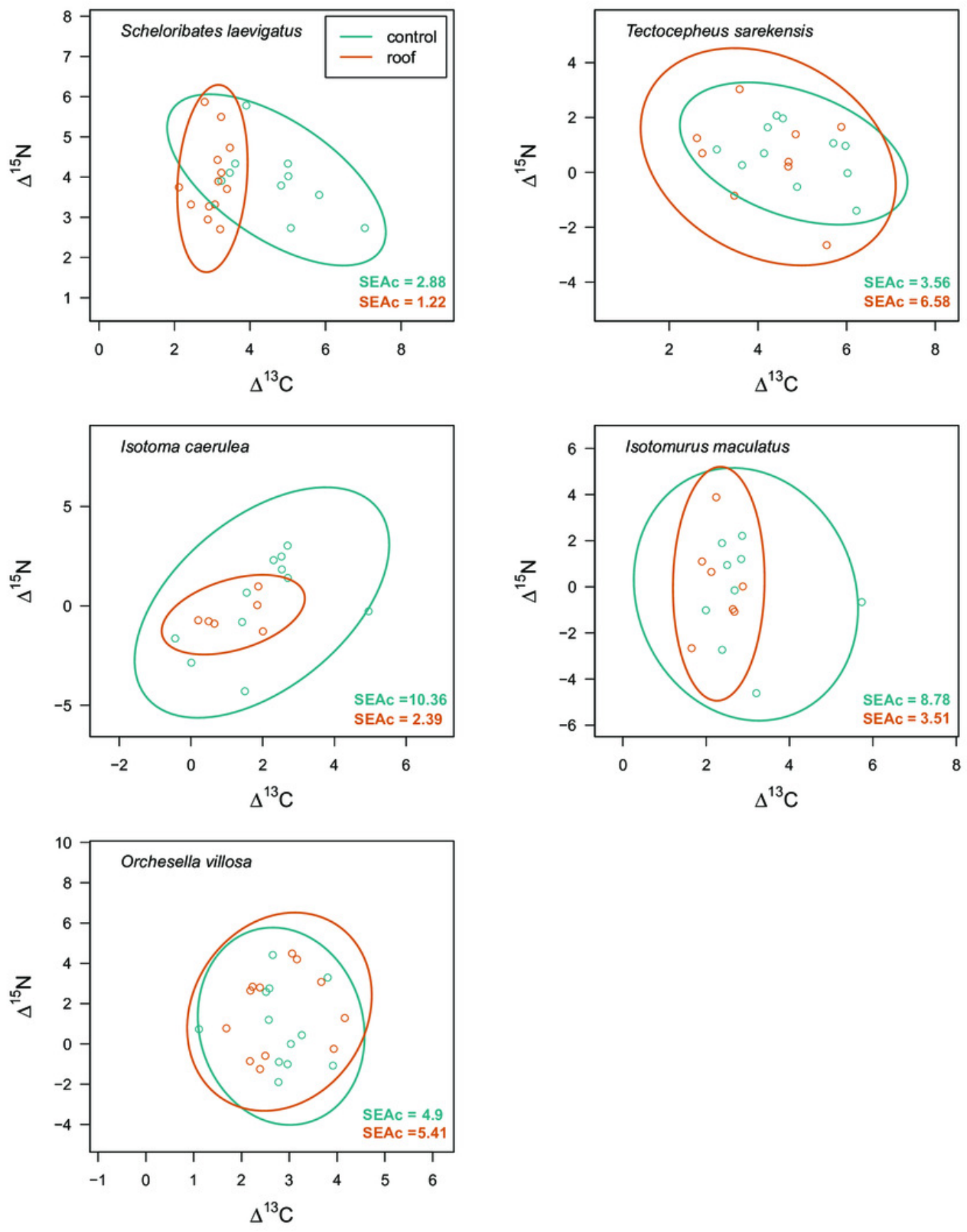


\section{Figure 6}

Isotopic niche space of Collembola and Oribatida in two different farming systems

Isotopic niche space of two oribatid mite (Scheloribates laevigatus, Tectocepheus sarakensis) and three Collembola species (Isotoma caerulea, Isotomurus maculatus, Orchesella villosa) in conventionally (conv, purple) and organically (org, green) managed fields. Standardized ellipses (SEAC) account for different sample sizes between taxa and small sample sizes per taxon and encompass approximately $95 \%$ of the data; see Methods. 

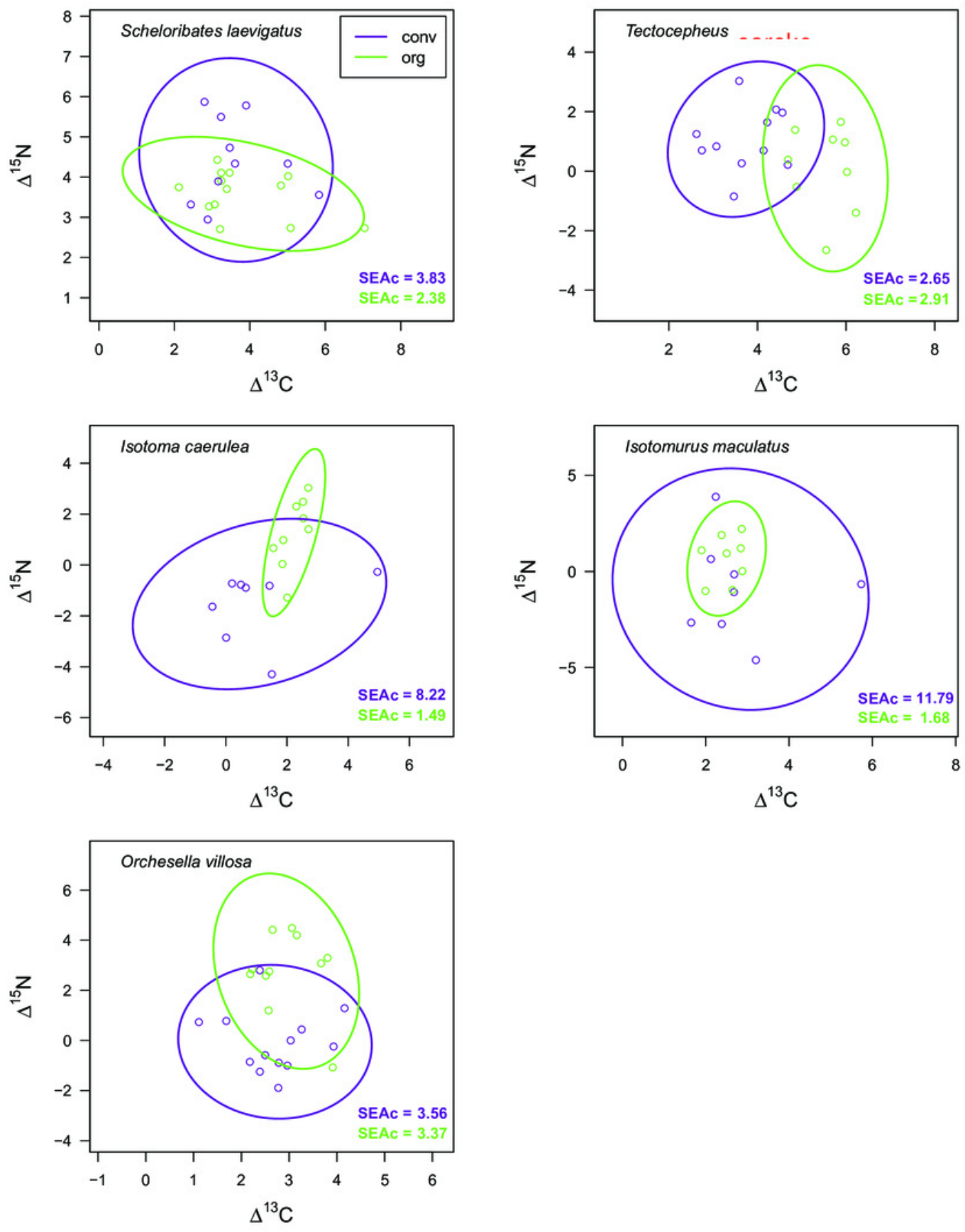


\section{Table 1 (on next page)}

Number of replicates for stable isotope measurements.

Per farming system (conventional, conv; organic, org) and drought treatment (control, roof). 


\begin{tabular}{|c|c|c|c|c|}
\hline \multirow[t]{2}{*}{ Species } & \multirow[t]{2}{*}{$\begin{array}{l}\text { Farming } \\
\text { system }\end{array}$} & \multirow[t]{2}{*}{ Drought } & \multicolumn{2}{|c|}{$\begin{array}{l}\text { number of } \\
\text { replicates }\end{array}$} \\
\hline & & & $\delta^{13} \mathrm{C}$ & $\delta^{15} \mathrm{~N}$ \\
\hline \multirow{4}{*}{ Isotoma caerulea } & \multirow{2}{*}{ conv } & control & 5 & 5 \\
\hline & & roof & 4 & 3 \\
\hline & \multirow{2}{*}{ org } & control & 6 & 6 \\
\hline & & roof & 4 & 3 \\
\hline \multirow{4}{*}{ Isotomurus maculatus } & \multirow{2}{*}{ conv } & control & 4 & 5 \\
\hline & & roof & 4 & 4 \\
\hline & \multirow[b]{2}{*}{ org } & control & 5 & 5 \\
\hline & & roof & 4 & 3 \\
\hline \multirow{4}{*}{ Orchesella villosa } & \multirow{2}{*}{ conv } & control & 6 & 7 \\
\hline & & roof & 7 & 7 \\
\hline & \multirow[b]{2}{*}{ org } & control & 6 & 6 \\
\hline & & roof & 5 & 6 \\
\hline \multirow{4}{*}{ Scheloribates laevigatus } & \multirow{2}{*}{ conv } & control & 4 & 4 \\
\hline & & roof & 6 & 6 \\
\hline & \multirow[b]{2}{*}{ org } & control & 7 & 6 \\
\hline & & roof & 7 & 7 \\
\hline \multirow{4}{*}{ Tectocepheus sarekensis } & \multirow{2}{*}{ conv } & control & 6 & 6 \\
\hline & & roof & 6 & 5 \\
\hline & \multirow{2}{*}{ org } & control & 5 & 5 \\
\hline & & roof & 4 & 4 \\
\hline
\end{tabular}

1 


\section{Table 2 (on next page)}

Results of LMMs on the effects of drought and farming system on the abundance, $\Delta^{13} \mathrm{C}$ and $\Delta^{15} \mathrm{~N}$ values of abundant species of the mesofauna.

Significant effects are given in bold. 
1

\begin{tabular}{|c|c|c|c|c|c|c|}
\hline & \multicolumn{3}{|c|}{$\Delta^{15} \mathrm{~N}$} & \multicolumn{3}{|c|}{$\Delta^{13} C$} \\
\hline & df & $\boldsymbol{F}$ & $\boldsymbol{P}$ & df & $\boldsymbol{F}$ & $\boldsymbol{P}$ \\
\hline Drought (D) & 1,12 & 2.74 & 0.124 & 1,12 & 3.09 & 0.104 \\
\hline Farming system (F) & 1,12 & 13.84 & 0.003 & 1,12 & 3.02 & 0.108 \\
\hline Species (S) & 4,71 & 32.56 & $<0.001$ & 5,83 & 43.02 & $<0.001$ \\
\hline$D \times F$ & 1,12 & 2.19 & 0.164 & 1,12 & 0.04 & 0.844 \\
\hline$D \times S$ & 4,71 & 0.72 & 0.58 & 5,83 & 2.92 & 0.018 \\
\hline $\mathrm{F} \times \mathrm{S}$ & 4,71 & 10.11 & $<0.001$ & 5,83 & 4.30 & 0.002 \\
\hline$D \times F \times S$ & 4,71 & 2.39 & 0.059 & 5,83 & 1.49 & 0.203 \\
\hline
\end{tabular}




\section{Table 3 (on next page)}

Results of LMM on the effects of drought, farming system and species identity on the abundance, $\Delta^{13} \mathrm{C}$ and $\Delta^{15} \mathrm{~N}$ values of the studied mesofauna species

Significant effects $(P<0.05)$ are given in bold. 


\begin{tabular}{|c|c|c|c|c|c|c|c|c|c|c|c|c|c|c|c|c|c|c|}
\hline & \multicolumn{3}{|c|}{$\begin{array}{c}\text { Scheloribates } \\
\text { laevigatus }\end{array}$} & \multicolumn{3}{|c|}{$\begin{array}{c}\text { Tectocepheus } \\
\text { sarekensis }\end{array}$} & \multicolumn{3}{|c|}{$\begin{array}{l}\text { Isotoma } \\
\text { caerulea }\end{array}$} & \multicolumn{3}{|c|}{$\begin{array}{l}\text { Isotomurus } \\
\text { maculatus }\end{array}$} & \multicolumn{3}{|c|}{$\begin{array}{c}\text { Orchesella } \\
\text { villosa }\end{array}$} & \multicolumn{3}{|c|}{$\begin{array}{c}\text { Mesaphorura } \\
\text { sp. }\end{array}$} \\
\hline & df & $\boldsymbol{F}$ & $\boldsymbol{P}$ & df & $\boldsymbol{F}$ & $\boldsymbol{P}$ & df & $\boldsymbol{F}$ & $\boldsymbol{P}$ & df & $\boldsymbol{F}$ & $\boldsymbol{P}$ & df & $\boldsymbol{F}$ & $\boldsymbol{P}$ & df & $\boldsymbol{F}$ & $\boldsymbol{P}$ \\
\hline \multicolumn{19}{|l|}{ Abundance } \\
\hline Drought (D) & 1,6 & 0.01 & 0.943 & 1,6 & 2.68 & 0.153 & 1,6 & 0.88 & 0.384 & 1,6 & 3.06 & 0.131 & 1,6 & 1.05 & 0.344 & 1,6 & 0.53 & 0.495 \\
\hline Farming system (F) & 1,6 & 1.80 & 0.228 & 1,6 & 0.01 & 0.910 & 1,6 & 0.83 & 0.396 & 1,6 & 0.13 & 0.728 & 1,6 & 1.63 & 0.249 & 1,6 & 1.79 & 0.229 \\
\hline$D \times F$ & 1,6 & 0.84 & 0.394 & 1,6 & 0.42 & 0.540 & 1,6 & 1.51 & 0.266 & 1,6 & 0.49 & 0.510 & 1,6 & 0.09 & 0.779 & 1,6 & 4.56 & 0.077 \\
\hline \multicolumn{19}{|l|}{ d13C } \\
\hline Drought (D) & 1,6 & 17.08 & 0.001 & 1,6 & 1.16 & 0.310 & 1,6 & 0.54 & 0.485 & 1,6 & 2.51 & 0.157 & 1,6 & 0.01 & 0.922 & 1,6 & 0.10 & 0.766 \\
\hline Farming system (F) & 1,6 & $<0.01$ & 0.960 & 1,6 & 14.11 & 0.005 & 1,6 & 1.16 & 0.312 & 1,6 & 0.88 & 0.379 & 1,6 & 0.36 & 0.562 & 1,6 & 0.43 & 0.536 \\
\hline$D \times F$ & 1,6 & 0.07 & 0.798 & 1,6 & 0.04 & 0.851 & 1,6 & 0.19 & 0.676 & 1,6 & 2.68 & 0.145 & 1,6 & 0.13 & 0.726 & 1,6 & 0.75 & 0.419 \\
\hline \multicolumn{19}{|l|}{ d15N } \\
\hline Drought (D) & 1,6 & 0.03 & 0.867 & 1,6 & 0.04 & 0.845 & 1,6 & 0.10 & 0.759 & 1,6 & 0.21 & 0.663 & 1,6 & 1.44 & 0.261 & - & - & - \\
\hline Farming system (F) & 1,6 & 4.30 & 0.062 & 1,6 & 2.82 & 0.132 & 1,6 & 15.47 & 0.008 & 1,6 & 2.69 & 0.145 & 1,6 & 15.90 & 0.003 & - & - & - \\
\hline$D \times F$ & 1,6 & 0.09 & 0.771 & 1,6 & 0.22 & 0.649 & 1,6 & 3.92 & 0.095 & 1,6 & 2.22 & 0.180 & 1,6 & 0.04 & 0.855 & - & - & - \\
\hline
\end{tabular}

